\title{
Poor mental health, poverty threaten Canadian kids: report
}

n Cite as: CMAJ 2019 September 23;191:E1065-6. doi: 10.1503/cmaj.1095814

Posted on cmajnews.com on Sept. 3, 2019

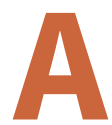

national non-profit is urging federal parties to tackle top threats to children's health.

One in three Canadian children does not enjoy a safe and healthy childhood, according to a new report by Children First Canada. The national non-profit is calling for federal action on the top 10 threats to children in Canada, including suicide, poverty and abuse.

Many Canadians are unaware of the harsh realities that children are facing across the country, said Stephanie Mitton, managing director of Children First Canada. Most rank Canada among the top 5 countries to raise kids, but compared to other wealthy nations, "we're actually 25 th out of 41 ," she said. When it comes to infant mortality, Canada ranks 30th out of 44 countries in the Organisation for Economic Cooperation and Development (OECD), behind all its peers in Europe.

"Kids are a quarter of the population but $100 \%$ of our future," Mitton said. "Addressing these issues isn't just important for them, but also for the country as a whole."

Preventable accidents and suicide remain the leading causes of death among young Canadians, according to the new report. Poor access to mental health supports is part of the problem, said Mitton. In Ontario, for example, one in five young people will experience some form of mental health problem, but only five in six of those kids will get the treatment they need.

Poverty is another persistent threat to Canadian children and the single largest determinant of their health, according to the report. Twelve percent of Canadian kids grow up in poverty, including half of Indigenous children. One in 10 families with young children lacks access to affordable, healthy food.

Many children also face violence in their homes and communities. One in three will experience some form of child

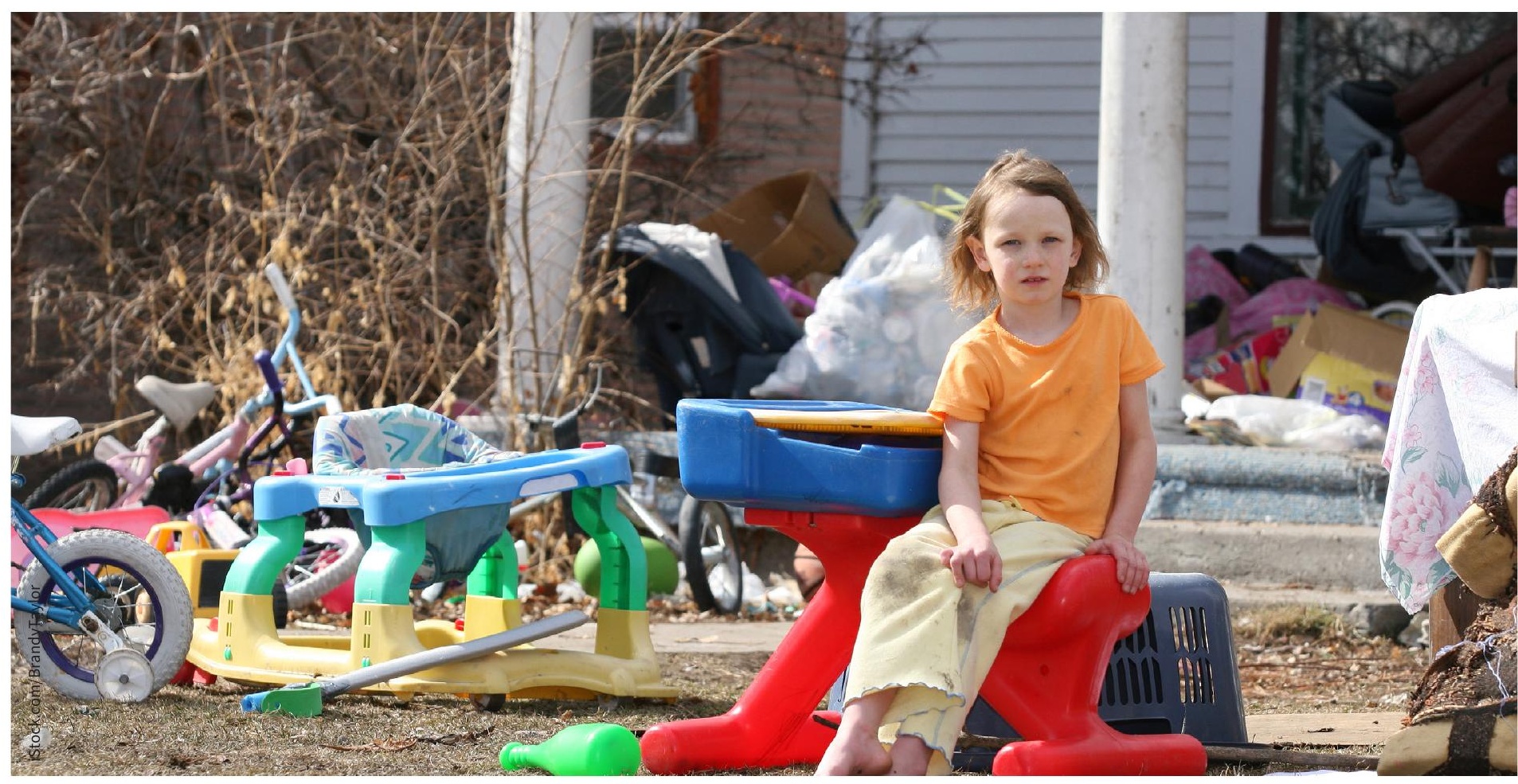

A national non-profit is urging federal parties to tackle top threats to children's health. 
abuse before age 16 , often at the hands of family members. The report also spotlights emerging threats from bullying and discrimination, citing 2014 data showing that one in five youth aged 15 to 20 experience cyberstalking, cyberbullying or both.

Other top threats include Canada's high rates of childhood obesity and falling rates of immunization. "There are so many different ways to tackle these prob- lems, but we need to get them prioritized and focused," Mitton said.

Children First Canada is calling for a pan-Canadian strategy for children to address the top threats facing children and ensure full implementation of children's rights charters, such as the Convention on the Rights of the Child. That strategy should include creating an independent federal commission to raise the profile of children in Canada and issuing a children's budget to improve accountability for money invested to improve their health.

"Just being able to do a proper analysis about that money will be a game changer in getting priorities right and getting measurable change," Mitton said.

Lauren Vogel, CMAJ 